\title{
PERFIL E COMPETÊNCIAS DO CONTROLLER EM EMPRESAS NO RECIFE
}

\section{CONTROLLER PROFILE AND COMPETENCES IN RECIFE COMPANIES}

\author{
0 artigo participou do II SIMPCONT - Simpósio de Controladoria da UFRPE, realizado em 25 e 26 de agosto de 2017, em Recife, PE
}

\section{RESUMO}

O estudo da Controladoria, bem como o conhecimento do perfil e competências exigidas aos controllers no desempenho de suas atividades, tem interessado inúmeros pesquisadores na atualidade. O objetivo deste trabalho foi levantar as competências mais utilizadas pelos Controllers no exercício de suas atividades em empresas no Recife, Pernambuco. A metodologia utilizada foi descritiva e exploratória, por meio de uma survey em 30 empresas. Foi utilizada a classificação de Fleury e Fleury (2011) de competências individuais: Sociais, Técnico-profissionais e de Negócio. As Sociais estão relacionadas ao comportamento social do indivíduo e capacidade de interagir com as pessoas; As Técnicas relacionadas com o conhecimento técnico da área, como: financeiro, contábil, de custos, etc.; E as competências de Negócio estão relacionadas à atuação do indivíduo junto à estratégia empresarial, desenvolvimento e inovação organizacional. Os resultados da pesquisa mostraram que os controllers são maioria mulheres, jovens, graduadas em Administração, Ciências Contábeis e Direito, com experiência na área entre 10 e 20 anos. As Competências Sociais foram identificadas com maior intensidade de uso dentre todas as demais, com praticamente nenhuma delas não sendo usada. Entre as competências de Negócio, a maioria dos participantes afirmou que usa muito as competências: tem capacidade de tomar decisão com imparcialidade e pensa e age estrategicamente. E entre as Competências Técnicas, a maioria usa muito as competências: gerencia indicadores de desempenho, assessora a cúpula administrativa e fornece suporte informacional à gestão organizacional, demonstrando que os profissionais que atam nas atividades de Controladoria estão desenvolvendo atividades gerenciais e de apoio à alta administração.

Palavras-chave: Controladoria, controllers, competências.

\begin{abstract}
The study of Controllership, as well as knowledge of the profile and skills required of controllers in the performance of their activities, has interested many researchers lately. This work aimed to identify the skills most used by Controllers in the exercise of their activities in companies in Recife, Pernambuco. Descriptive and exploratory methodology was used through a survey conducted in 30 companies. Fleury and Fleury (2011) classification was used for individual competences: Social, Technical-professional and Business. Social Competences relate to the individual's social behavior and his/her ability to interact with people; Technical-professional competences relate to technical knowledge of the field such as financial, accounting, costs, etc.; and Business Competences relate to the individual's performance in the corporate strategy, development and organizational innovation. Survey results showed that controllers are mostly young women, graduates in Business Administration, Accounting and Law, with 10-20 years of field experience. Social Competences were identified as more intensely used among all others, with practically all of them being used. Among Business Competences, most participants said they use their skills a lot: they have the ability to make decisions impartially and think and act strategically. And among Technical Competences, most of them use their skills a lot: they manage performance indicators, advise the administrative leadership, and provide informational support to organizational management demonstrating that the professionals who work in Controller activities are developing management and support activities for senior management.
\end{abstract}

Keywords: Controllership, controllers, competences
Tânia Nobre Gonçalves Ferreira Amorim

Doutora em Administração pela Universidade Federal da Paraíba (UFPB). Mestre em Administração Pública pela Universidade Federal Rural de Pernambuco (UFRPE). Graduada em Administração pela Universidade Federal de Pernambuco (UFPE). Professora Associada da UFRPE e Professora Associada aposentada da UFPE. Leciona disciplinas de Gestão de Pessoas, Liderança, Administração Geral e Competências e Desempenho, na graduação em Administração e Mestrado em Controladoria. Contato: R. Manuel de Medeiros, $s / n$, Recife - PE, CEP: 52171-900. E-mail: tanobre@gmail.com

\section{Anália Regina de Lima Oliveira}

Mestra em Controladoria pela Universidade Federal Rural de Pernambuco (UFRPE). Graduada em Ciências Contábeis pela Faculdade de Olinda (Focca). Contato: R. Manuel de Medeiros, $s / n$, Recife - PE, CEP: 52171-900. E-mail: annalialima@gmail.com

\section{Suely Maria Silva Manzi}

Mestra em Controladoria pela Universidade Federal Rural de Pernambuco (UFRPE). Especialista em: Administração com Ênfase em Marketing pela Universidade Federal Rural de Pernambuco (UFRPE). Bibliotecários de Instituições de Ensino Superior pela Universidade Católica de Minas Gerais e Administração de Bibliotecas pela Universidade do Amazonas. Bacharel em Biblioteconomia pela Universidade Federal de Pernambuco (UFPE) e Ciências Sociais pela Universidade Católica de Pernambuco (UNICAPE). Bibliotecária da UFRPE. Contato: R. Manuel de Medeiros, s/n, Recife - PE, CEP: 52171-900. E-mail: sulamanzi@gmail.com
Melina França Cabral Bemfica
Mestra em Controladoria pela Universidade Federal Rural de Pernambuco (UFRPE). MBA em Gerência Contábil, Perícia, Auditoria e Controla- doria pela Faculdade Internacional de Curitiba (FACINTER). Graduada em Ciências Contábeis pela Universidade Federal de Pernambuco (UFPE). Trabalhou cinco anos com auditoria in- dependente. Atualmente é Analista Ministerial na área de Ciências Contábeis no Ministério Público do Estado de Pernambuco. Contato: Av. Consul Joseph Noujaim, 146, Pina - Recife/PE, SC, CEP: 51110-150. E-mail: mpmelina@gmail.com 


\section{INTRODUÇÃO}

Os impactos resultantes do mundo globalizado, da expansão geográfica das organizações e sua verticalização, do avanço da tecnologia da informação e o consequente aumento da complexidade operacional, além da facilidade de acesso a novos e maiores mercados, trouxeram ao ambiente de negócios uma nova realidade, em que a capacidade de adaptação é indispensável na determinação de quem sobrevive ou se exclui do mercado, segundo Lourensi e Beuren (2011). Esta realidade provoca reflexos na maioria das profissões e o contador é um dos profissionais que precisa se reinventar perante esta nova realidade do mercado.

Reis et al. (2015) salientam que diante dessa nova realidade, o profissional da área contábil precisa desenvolver principalmente habilidades e competências pessoais, com ética, responsabilidade e elevado comprometimento com a profissão, com base em sólidos conhecimentos teóricos em sua área e áreas afins.

Takatori (2004) descreve a Contabilidade como uma ciência rica em base conceitual, interagindo de forma multidisciplinar com os demais ramos de conhecimento. Em busca a uma via alternativa à contabilidade tradicional, cuja base conceitual é inadequada para modelar as informações destinadas ao uso dos gestores, surge a Controladoria, como uma evolução da contabilidade tradicional, que tem a função de colaborar na formação das estratégias, fazendo com que os diversos setores interajam.

A controladoria tem a função de coordenar os esforços dos gestores para "garantir o cumprimento da missão da empresa e assegurar sua continuidade, gerando informações relevantes, fidedignas e tempestivas para tomada de decisões dos gestores" (NASCIMENTO et al. 2005, p.03). Anthony e Govindarajan (2002) defendem que a controladoria desempenha importante papel na elaboração dos planos estratégicos e orçamentários das organizações modernas.

Contudo, segundo Lunkes, Schnorrenberger e Rosa (2013) o surgimento da Controladoria se deu a partir da prática gerencial, e evoluiu inicialmente, sem ter uma definição clara de sua área de atuação, portanto, o seu entendimento foi muito influenciado pelas reações à aplicação prática. Já Lunkes, Schnorrenberger e Gasparetto (2010) defendem que a controladoria é uma área de estudos que ainda exige uma consolidação de definições e conceituações claras, incluindo um cabedal básico de suas funções.

Então, a globalização tornou o mercado muito competitivo, fazendo com que os empresários tenham mais cuidado e comprometimento em sua gestão organizacional, para que as empresas se mantenham no mercado. A falta de informações e de preparo dos gestores fazem com que decisões erradas sejam tomadas, prejudicando a sustentabilidade da empresa (FLESCH, 2010). Broadben e Laughlin (2005) defendem que a controladoria assume papel de grande importância, apoiando os gestores no planejamento e controle de gestão.

Beuren e Miller (2010), por sua vez, salientam que ao implantar a controladoria, esta pode ocorrer em forma de um órgão ou setor, quando deverão ser definidos missão e objetivos, os quais deverão estar de acordo com as necessidades da empresa. Mas também pode ser apenas implantada na forma de ampliação das atividades contábeis e gerenciais, que incluam a preocupação mais efetiva com os controles internos e elaboração de informações que subsidiem o processo decisório organizacional.

Mais recentemente a Controladoria se mostra cada vez mais relevante no Brasil e no mundo. Nos últimos anos, Sousa e Bassolli (2013) defendem que se pode observar um número crescente de pesquisas sobre o tema, talvez pela abrangência e variedade de tarefas desenvolvidas pela área de estudo, e também, orientar o desenvolvimento dos profissionais que nela atuam, em muitas empresas denominados de controllers. Para Lunkes e Schnorrenberger (2009) e Lunkes, Schnorrenberger e Gasparreto (2010), o controller é um profissional que exerce diferentes atividades, variando conforme a organização.

Diante desse contexto de constantes mudanças, muitos gestores buscam orientações quanto à direção e ao controle de suas atividades ao controller, porque ele pode ser responsável pelo sistema de informações da empresa, o qual irá subsidiar análises e decisões gerenciais, com base em eventos passados, o desempenho atual e cenários futuros (BEUREN, 2002). Contudo, não se tem um consenso sobre as competências desse profissional, que variam substancialmente em resposta às demandas organizacionais.

Assim, a importância para a inserção de profissionais que atuam na controladoria tem aumentado nas empresas mundo afora, e no Brasil não seria diferente. Não necessariamente há a necessidade de constar um órgão específico de Controladoria na estrutura organizacional, mas suas atividades estão sendo requeridas para que as organizações consigam se manter nesse mercado competitivo e com mais exigências de eficiência e eficácia.

Contudo, não há uma formação específica para o profissional que atua na Controladoria das organizações, também porque não se tem uma consolidação de quais são as funções e responsabilidades desse profissional, que varia muito, dependendo do tipo de empresa em que atua, seu ramo de atividade, porte, modelo de gestão e estrutura organizacional estabelecida.

A princípio se tem a ideia de que o controller teria uma formação em Ciências Contábeis, pois se entende que a Controladoria a teria como base, mas com o passar dos anos, as exigências e competências que estes profissionais passaram a assumir em muitas organizações, os levaram a um maior nível de complexidade conceitual, uma vez que estão deixando de participar eminentemente das decisões e atividades operacionais de controle organizacional, para assumirem um papel mais efetivo de staff aos gestores e todo o processo gerencial. Assim, estão sendo procurados para assumirem as atividades de Controladoria muitos profissionais de áreas afins como Administração e Economia. 
Portanto, qual seria o perfil desse profissional, para atender a todas as demandas das mais variadas organizações, públicas e privadas, de portes e segmentos variados, é uma questão que ainda não se tem uma resposta definitiva. Agravando essa realidade, o Brasil, país continental, possui realidades socioeconômicas muito diversas entre suas regiões e organizações.

Então, a necessidade por um profissional capaz de gerir e controlar as informações de uma empresa de forma eficiente, levanta o questionamento de qual seria o perfil e quais as competências que o controller deve possuir na atualidade? O objetivo da pesquisa que deu origem a este trabalho foi exatamente levantar as competências mais utilizadas pelos Controllers no exercício de suas atividades em empresas no Recife, em Pernambuco. Com isto, este estudo pretende contribuir para o entendimento sobre as competências necessárias a este profissional que vem sendo requerido com maior intensidade e relevância nas organizações da atualidade.

\section{REFERENCIAL TEÓRICO}

\subsection{Entendimento sobre Controladoria e Controllers}

Conforme Martins et al. (2012) a controladoria no Brasil surgiu a partir da instalação de multinacionais norte-americanas no país, em meados do século XX, quando também surgiu a função de controller. Os profissionais dessas empresas, baseados em suas teorias e práticas contábeis, passaram a treinar os profissionais no Brasil, com sistemas de informações capazes de atender a qualquer usuário, com adequado sistema de controle das operações, os quais passaram a incluir inúmeras novas e melhores práticas de gestão, que proporcionam maior eficácia nas decisões organizacionais. Flesch (2010) define a controladoria como área de conhecimento, conceituada como um conjunto de princípios, procedimentos e métodos oriundos de outras ciências, que se preocupa com a orientação das empresas para a obtenção da eficácia. Já Oliveira, Perez Jr. e Silva (2011, p.5) entendem a “Controladoria como o departamento responsável pelo projeto, elaboração, implementação e manutenção do sistema integrado de informações operacionais, financeiras e contábeis”.

Para Borinelli (2006), a Controladoria abrande funções contábil, gerenciais, estratégicas, custos, tributária, controles internos, de riscos e de gestão da informação, primordialmente. Beuren, Bogoni e Fernandes (2008) pesquisaram as funções da controladoria em 26 dissertações em contabilidade do Brasil e identificaram que as principais funções são: gestão de informações, contábil, gerencial, custos, controles internos e tributação, proteção e controle de ativos. Já Guimarães et al. (2009) em seus estudos, identificaram que a controladoria dá suporte à gestão de riscos, com objetivo de reduzi-los. Brewer (2008, p. 36) afirma que a controladoria se baseia em quatro pilares: liderança, gestão estratégica, alinhamento operacional, melhoria e aprendizado contínuos; e, "em última instância, a responsabilidade dos controllers é gerar valor para os acionistas".

A Controladoria, então, segundo Callado e Amorim (2017, p. 61) "é responsável pelo controle do processo de gestão, gerando e fornecendo informações diversas que podem ser de natureza operacional e estratégica, econômica, financeira e patrimonial, para a tomada de decisões", a qual foi adotada para fins deste trabalho, destacando que as informações podem ter cunho contábil, gerenciais, estratégicas, tributárias, de controles internos, de riscos e de alinhamento gerencial, apoiadas por um bom sistema de gestão da informação.

O controller é um profissional que atua em diversas áreas, gerenciando e fornecendo informações necessárias para tomada de decisões, Bragg (2009), participa da gestão estratégica da tecnologia de informação dando suporte de TI na gestão de E-business, gestão de documentos e gestão de contratos, em organizações bancárias em que estudaram. Para Borinelli (2006) o profissional responsável pela controladoria atua em várias funções sendo as principais: contábil, gerencial, de custos, tributária, de controle interno, de risco e gestão de informações.

Duque (2011) afirma que o papel do controller no Brasil era visto como necessário até a década de 90, apenas nas empresas multinacionais ou de grande porte. Com o passar dos anos, o controller é requisitado, de pequenas empresas a multinacionais, e as habilidades e competências dos profissionais da controladoria sofrem grandes variações, de acordo com a necessidade organizacional, com demandas que irão definir como e quais tarefas serão desenvolvidas.

Na visão de Dalmacio (2007), a princípio a controladoria ficou conhecida como sendo responsável pela contabilidade das empresas, pela elaboração de relatórios gerencias e orçamentos, pelo custeio dos produtos, apuração de impostos, cumprimento de normas, mudando ao longo do tempo e suas funções foram se diversificando. Padoveze e Benedicto (2005) defendem que a controladoria pode ser entendida como o exercício da função contábil e gerencial, acrescido de controle de sistemas de informações, para monitoramento da estratégia e gestão do risco.

Lunkes, Schnorrenberger e Rosa (2013) também afirmam que inicialmente a controladoria era baseada na contabilidade, mas com o tempo foi ampliando sua atuação, incorporando funções de planejamento e sistemas de informação. Para eles, com base em seus estudos, que buscaram levantar o entendimento tanto no âmbito empírico como no teórico, podem-se sintetizar as principais funções da Controladoria como funções empíricas, consolidadas e da literatura. As funções empíricas são: contábil, controle, administração de impostos, elaboração e interpretação de relatórios, planejamento e controle interno. As funções consolidadas são: planejamento, controle, contábil e elaboração e interpretação de relatórios. E as funções da literatura são: controle, planejamento, sistemas de informações contábil e elaboração e interpretação de relatórios.

Segundo Fernandes e Galvão (2016, p.9) é "evidente a importância que tem a controladoria para as pessoas que conduzem os negócios. Independente de ser estruturada como um departamento formal ou não”. Hamdan (2011) lem- 
bra que o tamanho da empresa afeta sua forma de gestão e consequentemente o grau de conservadorismo dos relatórios financeiros elaborados por elas.

Portanto, a Controladoria ganhou mais e mais espaço na gestão organizacional, não mais apenas em grandes empresas, e nem sempre como um órgão ou setor estruturado, mas como uma área de conhecimento que não é mais meramente operacional, porque passou a assessorar a gestão organizacional nos mais diversos níveis decisórios e contribuir para decisões tanto operacionais como estratégicas. Contudo, autores como Lambert e Sponem (2012) e Rahman e Ahmed (2012) lembram que não é tão comum encontrar controllers efetivamente atuando como parceiros do negócio e que essa mudança de papel ocorre principalmente nas grandes empresas.

Diante do que foi apresentado, confirma-se que a Controladoria ainda é uma área que está em desenvolvimento e confirmação de suas responsabilidades, bem como de sua atuação nas organizações modernas. Muitos estudos ainda identificam uma atuação muito rudimentar da Controladoria, a qual atua basicamente nos controles internos e em nível operacional. Outros, porém, em menor número, conseguem identificar uma atuação da Controladoria como parceiro estratégico, que atua efetivamente como staff da gestão, coletando, analisando e fornecendo à cúpula organizacional, informações que contribuam para a elaboração de estratégias e tomada decisão organizacional.

\subsection{Entendimento sobre Competências e Competências dos Controllers}

O tema competências vem sendo estudado há alguns anos, mas ainda é muito controvertido, porque é abrangente e vários autores o definem de formas diversas (RUAS et al., 2005; MEDEIROS, 2007). As competências podem ser classificadas de diversas formas, dependendo dos autores, mas inicialmente podem ser subdivididas em organizacionais e individuais. Dutra (2004) afirma que existe uma relação entre as competências organizacionais e individuais, pois as organizacionais decorrem do nível de desenvolvimento organizacional, patrimônio de conhecimentos e vantagens competitivas. Já nas competências individuais, existe uma relação contínua de troca, em que a organização transfere seu patrimônio para as pessoas e vice-versa.

Há duas abordagens distintas sobre o entendimento das competências, que são baseadas na visão europeia e americana, sintetizadas no quadro 1.

Quadro 1: Conceitos de Competência na visão Europeia e Americana

\section{O QUE É COMPETENCE? (VISÃO EUROPEIA)}

Visão interpretativa, holística e/ou multidimensional. Competência é parte dos processos sistemáticos de aprendizagem, relação entre trabalho e educação, e capacidade de realização em dado contexto.

Agregação de valor do funcionário à empresa que o contrata.

Dominada por instituições ou organizações e concedidas para o indivíduo.

Realização que se pode transferir.

Padrões para funções de trabalho e profissões.

A ênfase é uma visão construtivista da aprendizagem.

Características do indivíduo.

Outputs do comportamento humanos (resultados e produtos).

Parry (1996): não podem ser confundidas com as características pessoais, pois são recursos adquiridos, permitindo destacar-se entre os demais, pelo desempenho.

Zarifian (2001): é uma inteligência prática que envolve iniciativa do sujeito. Reconhecida através da atuação, iniciativa e responsabilidade em situações profissionais com as quais se depara.

Le Boterf (2007): a competência implica ação e envolvimento no ambiente de trabalho; disposição para resolver problemas. Deriva de fatores inerentes ao próprio indivíduo (biografia, socialização, formação e experiência profissional). Tem três eixos: a pessoa, sua formação educacional e experiência profissional.

\section{O QUE É COMPETENCY? (VISÃO AMERICANA)}

Visão funcionalista, comportamental e/ou racionalista. Referência ao mercado de trabalho e focada em desempenho. Estoque de qualificações, que credenciam para exercer determinado trabalho.

Repertórios comportamentais que as pessoas trazem para o trabalho.

Contida no indivíduo e trazida para a organização.

Realização que se pode estimular.

Conjunto de qualificações do indivíduo para executar um trabalho com superior de desempenho.

A ênfase é uma perspectiva cognitiva da aprendizagem.

Desempenho no cargo.

Inputs conjunto de capacidades (CHA - conhecimentos, habilidades e atitudes) de cada indivíduo.

McClelland (1973): são as habilidades, os conhecimentos e as aptidões. Características implícitas da pessoa que realiza as tarefas com grande desempenho.

Boyatizis (1982, p. 23): Competências são aspectos verdadeiros ligados à natureza humana. "São comportamentos observáveis que determinam, em grande parte, o retorno da organização."

Spencer e Spencer (1993, p. 9): "refere-se à características intrínsecas ao indivíduo que influencia e serve de referencial para seu desempenho no ambiente de trabalho." Não se relaciona com as capacidades, mas com a disposição e capacidade do empregado usar suas capacidades em situações específicas.

Fonte: Baseado em: Sparrow e Bognanno (1994) apud Cardoso (2006 p.67); Conde (2001); Garavan e McGuire (2001); Batista e Cançado (2017). 
Dutra et al. (2008, p.3) afirmam que só se pode "falar de competência apenas quando há competência em ação, traduzindo-se em saber ser e saber mobilizar o repertório individual em diferentes contextos." "Nesta perspectiva, as competências da empresa colocadas aqui numa dimensão coletiva e organizacional aparecem como importantes fatores para as escolhas das estratégias de competição"(RUAS et al., 2005, p.2).

Conforme Amorim (2014), as empresas necessitam cada vez mais se especializarem, buscar conhecer profundamente o ambiente que estão inseridas e quais áreas suas competências são efetivamente valorizadas. Precisam também de identificar profissionais capacitados que desenvolvam todo seu potencial. Portanto, as competências exigidas dos profissionais tornam-se postos-chave para se conseguir diferenças competitivas, através de uma Gestão de Pessoas eficiente.

Amorim e Silva (2011, p.110) entendem competência como:

Um enfoque que correlaciona temas como: mobilizar, integrar e transferir conhecimentos da capacidade humana na aplicação do saber do conhecimento, o saber fazer das habilidades, e o saber agir responsável e reconhecido das atitudes. Todos esses saberes afetam as pessoas e a organização, em um aprendizado compartilhado, agregando valor econômico, como também pessoal e social. A competência pode ser mensurada, quando comparada a padrões estabelecidos pelas organizações e, também, pode ser melhorada, por meio de treinamentos e desenvolvimento, servindo aos propósitos da organização (AMORIM; SILVA, 2011, p.110).

Fleury e Fleury (2011) classificam as competências individuais em três categorias: a) Competências de Negócio, relacionadas à interação da empresa com o entendimento das oportunidades, ameaças, pontos fortes e fracos do negócio, orientadas para as necessidades e as exigências do mercado (clientes e concorrentes); b) Competências Técnico-Profissionais com ênfase nos inputs do conhecimento ou experiência técnica na área de atuação (pesquisa, conhecimento do produto, finanças, etc); c) Competências Sociais que enfatizam a interação com as pessoas, processos de negociação, trabalho em equipe, exposição de ideias, motivação, etc.

Fernandes e Comini (2008) definem as competências individuais como: a) Conhecimentos (saber): conjunto de informações, fatos, conceitos e princípios; b) Habilidades (o saber fazer): conjunto de comportamentos relacionados à perícia, capacidade e domínio de certas áreas que permitem ao profissional desempenhar plena e satisfatoriamente determinadas atividades; c) Atitudes (o saber agir): relacionam-se ao comportamento demonstrado pela pessoa em situações específicas; D) Valores: concepções e crenças racionalizadas que influenciam escolhas pessoais.

Para atender às necessidades da área de controladoria, o profissional precisa ter uma série de competências pessoais, técnicas e de negócio, atendendo ao perfil exigido pelas empresas. Koliver (2005) descreve que o controller deve ter uma visão ampla, porque sua atuação não se restringe a uma função específica, mas abrange a atuação e controle das diversas áreas da organização. Assim, a função do controller no Brasil, tem relevância tanto no meio acadêmico como no mercado, procurando profissionais especializados, com visão de gestão, planejamento gerencial, fiscal, financeiro e de contabilidade.

Os impactos resultantes do mundo globalizado, da expansão geográfica das organizações e sua verticalização, do avanço da tecnologia da informação e o consequente aumento da complexidade operacional, para Lourensi e Beuren (2011), além da facilidade de acesso a novos e maiores mercados, trouxeram ao ambiente de negócios uma nova realidade, em que a capacidade de adaptação é indispensável na determinação de quem sobrevive ou se exclui do mercado.

Figueiredo e Caggiano (2008, p.13) elencam os requisitos do controller como: "bom conhecimento do ramo de atividade; conhecimento da história da empresa; habilidade para analisar dados contábeis e estatísticos e habilidade de bem expressar oralmente e por escrito”. Nascimento e Reginato (2010, p.142) destacam seus principais atributos: “capacidade de liderança, ética profissional, capacidade de comunicação e poder de síntese, inclinação para a cooperação e disponibilização, imparcialidade, ponderação e discrição, visão sistêmica, capacidade de persuasão, visão crítica e consciência de suas próprias limitações”. Emsley (2005, p. 158) afirma: controllers são conhecidos por múltiplos papéis, "descritos em termos de registro de resultados, atenção à direção, e resolução de problemas".

Já Fernandes e Galvão (2016, p.15) defendem que o controller.

reúne as qualificações técnicas e habilidades pessoais necessárias para realizar as funções da controladoria, como planejamento, controle, informação, contabilidade, entre outras... alguém com condições de implantar e interpretar os instrumentos necessários para uma boa administração, como: orçamento, custos, contabilidade, entre outros (FERNANDES; GALVÃO, 2016, p.15).

Em síntese, as competências do controller são: elaboração de orçamentos; atividades de controle interno; elaboração de relatórios contábeis; auditoria interna; avaliação de desempenho econômico; sistemas de contabilidade; relatórios de governo e gestão fiscal (HORNGREN, SUNDEM e STRATTON, 2004; KOLIVER, 2005; ZONI; KENNETH, 2007; VARGAS; BEUREN, 2012; LUNKES, SCHNORRENBERGER e ROSA, 2013; CAVALCANTI et al., 2012; SCHMIDT; SANTOS, 2014).

\section{PROCEDIMENTOS METODOLÓGICOS}

Inicialmente foi realizada uma revisão bibliográfica sobre a temática em estudo. A necessidade por um profissional capaz de gerir e controlar as informações de uma empresa de forma eficiente e eficaz, levanta o questionamento de qual 
seria o perfil e competências que o controller deve possuir? Assim, o objetivo da pesquisa foi levantar as competências mais utilizadas pelos Controllers no exercício de suas atividades em empresas de Recife, Pernambuco.

Os dados pesquisados são de natureza descritiva e exploratória, com uma pesquisa operada por survey. Segundo Gil (2010) as pesquisas de levantamento ou survey se caracterizam pela interrogação das pessoas ou informações que se deseja conhecer. As pesquisas descritivas e exploratórias são habitualmente utilizadas por pesquisadores sociais preocupados com a atuação prática e se justificam neste estudo por ainda não se ter um consenso sobre as competências dos controllers.

Buscando identificar o perfil e as competências do controller foram elencadas 50 empresas diversas, escolhidas aleatoriamente, em atuação no Recife, que foram visitadas e convidadas a participarem da pesquisa. Conseguiu-se realizar entrevista estruturada em 30 empresas, a partir de um questionário, roteiro, contendo os seguintes aspectos: caracterização da empresa, perfil do responsável pelos controles gerais ou controller, e as competências mais utilizadas por este profissional, a partir de uma lista das principais competências atribuídas aos controllers, distribuídas numa escala Likert (não uso; uso pouco; geralmente uso e uso muito).

Foi utilizada a classificação de Fleury e Fleury (2001; 2011) e Fleury (2009) que divide as competências em três categorias: a) Competências de Negócio, as que estão relacionadas à interação da empresa com o ambiente, pontos fortes e fracos do negócio, orientadas para as exigências do mercado; b) Competências Técnico-Profissionais que são os inputs do conhecimento ou experiência técnica, com relação à área de atuação; e c) Competências Sociais que enfatizam a interação das pessoas nos processos organizacionais, como no trabalho em equipe, relações interpessoais dentre outras.

Foram listadas 59 competências subdivididas em 20 competências Técnicas, 21 competências Sociais e 18 de Negócio, baseadas no levantamento bibliográfico estudado e detalhadas no quadro 2.

Quadro 2 - Relação das competências Técnicas, Sociais e de Negócio.

\section{COMPETÊNCIAS TÉCNICAS}

Conhecimentos na área financeira

Conhecimentos na área contábil

Conhecimentos na área fiscal/tributária

Conhecimentos na área de tecnologia da informação

Conhecimentos na área de Recursos Humanos

Conhecimentos na área comercial/ produção

Elabora diretrizes de controles internos

Elabora o Orçamento Anual

Gerencia indicadores de desempenho

Supervisiona as atividades nas áreas de custos

Fornece dados contábeis oportunos e precisos

Supervisiona o funcionamento dos setores

Supervisiona a contabilidade

Fornece suporte informacional à gestão

Elabora relatórios gerenciais

Assessora a cúpula administrativa

\section{COMPETÊNCIAS SOCIAIS}

Interage bem com as pessoas

Tem integridade e confiança

Tem flexibilidade nas relações interpessoais

Sabe formar equipes cooperativas e comprometidas

Estimula o desenvolvimento profissional da equipe

Comunica-se, oralmente com clareza e objetividade

Tem capacidade de prever problemas interpessoais

Sabe negociar com pessoas

Estimula o aprendizado da equipe

Tem capacidade de solucionar problemas interpessoais

Possui liderança e sabe gerir pessoas

Escreve com clareza e objetividade

É persistente e não desiste frente aos obstáculos

Tem postura proativa e realizadora

Busca o autodesenvolvimento

Tem capacidade de autocrítica

\section{COMPETÊNCIAS DE NEGÓCIO}

Pensa e age estrategicamente

Tem orientação para Resultados

Promove ações de interação da empresa com seu ambiente

Sabe organizar o tempo para realizar diversas atividades

Tem foco na qualidade em todas as decisões que toma

Busca melhoria contínua dos processos em que participa

Tem capacidade de tomar decisão com imparcialidade

Realiza a gestão de contratos

Faz a análise de risco organizacional

Interage com os prestadores de serviços/ terceirizações

Relaciona-se com outras empresas parceiras

Realiza o acompanhamento técnico dos projetos

Tem orientação para o Cliente/Fornecedor

Age com responsabilidade socioambiental

Tem preocupação com segurança e saúde na empresa

Busca inovação organizacional (Pesquisa \& Desenvolvimento) 


\begin{tabular}{|c|c|c|}
\hline COMPETÊNCIAS TÉCNICAS & COMPETÊNCIAS SOCIAIS & COMPETÊNCIAS DE NEGÓCIO \\
\hline Realiza análise de custos & $\begin{array}{l}\text { Gerencia conflitos no ambiente de } \\
\text { trabalho }\end{array}$ & $\begin{array}{l}\text { Promove ações de interação da empresa } \\
\text { com seu ambiente }\end{array}$ \\
\hline Realiza análise de índices contábeis & Tem controle emocional & $\begin{array}{c}\text { É criativo para solucionar problemas em- } \\
\text { presariais }\end{array}$ \\
\hline $\begin{array}{c}\text { Elabora o Planejamento Financeiro } \\
\text { Organizacional }\end{array}$ & $\begin{array}{c}\text { Adapta-se bem às mudanças e novas } \\
\text { situações }\end{array}$ & \\
\hline \multirow[t]{2}{*}{ Age como consultor interno } & Sabe ouvir os outros & \\
\hline & Sabe trabalhar em equipe & \\
\hline
\end{tabular}

Fonte: Baseado nos dados da pesquisa.

O elevado quantitativo de competências elencadas se deu em virtude de que no levantamento bibliográfico foi identificado que o controller possui funções variadas, diversificadas e multifacetadas, por atuar tanto de forma operacional como gerencial, passando a atuar mais efetivamente como apoio à gestão organizacional.

\section{ANÁLISE DOS RESULTADOS}

O primeiro segmento pesquisado foi buscar conhecer o perfil organizacional das empresas pesquisadas e a maioria é formada por médias e grandes empresas, seguindo a classificação do SEBRAE (Serviço Brasileiro de Apoio às Micro e Pequenas Empresas), destacando que 3\% não souberam identificar. Quanto ao ramo de atividade da amostra trabalhada a metade foi formada por prestadoras de serviços, conforme detalhado no quadro 3.

\begin{tabular}{|c|c|c|}
\hline Variável & Níveis da variável & $\%$ \\
\hline \multirow{3}{*}{ Porte da Empresa } & Pequena & $40 \%$ \\
\hline & Média & $30 \%$ \\
\hline & Grande & $27 \%$ \\
\hline \multirow{3}{*}{ Ramo de atividade } & Prestação de Serviços & $50 \%$ \\
\hline & Comércio & $43,3 \%$ \\
\hline & Indústria & $6,7 \%$ \\
\hline \multirow{2}{*}{ Possui Controladoria } & Sim & $40 \%$ \\
\hline & Não & $60 \%$ \\
\hline
\end{tabular}

Fonte: Elaborado pelas autoras com base nos dados da pesquisa

O profissional responsável pelos controles gerais, recebe diversos nomes nas empresas pesquisadas como: Controller, Coordenador de controladoria, Gerente de controladoria ou é o próprio sócio da empresa que realiza algumas atividades da área, uma vez que apenas $40 \%$ da amostra possui uma unidade de controladoria instalada.

Esses dados confirmam o que Lunkes, Schnorrenberger e Gasparreto (2010) defendem de que o controller é um profissional que exerce diferentes atividades, variando conforme a organização, inclusive sua nomenclatura. Bragg (2009, p. 13) também afirma que "o trabalho do controller varia drasticamente de acordo com o tamanho da empresa e com a existência de outros gerentes no lugar que lidam com as mesmas funções”. E também Fernandes e Galvão (2016) que defendem a importância da controladoria, independente da existência de um setor específico.

No perfil do controller, pode-se observar que a maioria dos entrevistados é do sexo feminino (66,7\%), o que não era esperado, uma vez que inúmeros estudos mostram predominância masculina entre os controllers como os de Machado et al. (2013) e Crispim, Cabral e Libonati (2011) e Amorim e Silva (2011). 


\begin{tabular}{|c|c|c|}
\hline VARIÁVEL & NÍVEIS DA VARIÁVEL & $\%$ \\
\hline Gênero & $\begin{array}{l}\text { Masculino } \\
\text { Feminino }\end{array}$ & $\begin{array}{r}50 \% \\
66,7 \%\end{array}$ \\
\hline Faixa Etária & $\begin{array}{l}\text { Até } 30 \text { anos } \\
\text { De } 31 \text { a } 40 \\
\text { De } 41 \text { a } 50\end{array}$ & $\begin{array}{l}13,3 \% \\
73,4 \% \\
13,3 \%\end{array}$ \\
\hline Formação Superior & $\begin{array}{l}\text { Sim } \\
\text { Não }\end{array}$ & $\begin{array}{c}100 \% \\
0 \%\end{array}$ \\
\hline
\end{tabular}

Fonte: Elaborado pelas autoras com base nos dados da pesquisa

Em termos da faixa etária, os profissionais pesquisados são jovens, todos os possuem formação superior, sendo 23,3\% em Ciências Contábeis, 23,3\% em Direito, 36,7\% em Administração de Empresas e 16,7\% em formações diversas. Nestes resultados talvez o ramo de atividade das empresas pesquisadas tenha influenciado de forma mais efetiva, uma vez que um terço da amostra era formado por empresas prestadoras de serviços jurídicos.

Dados semelhantes não foram identificados em outros estudos, talvez pela peculiaridade da amostra trabalhada, mas Borinelli (2006), Beuren, Bogoni e Fernandes (2008) identificaram em seus estudos, forte presença de Contadores e Administradores nas funções de controladoria.

Já em termos de experiência profissional, os controllers em maioria tem de 10 a 20 anos. Estes dados podem sugerir que esses profissionais tenham se dedicado à Controladoria desde o início de suas carreiras, uma vez que são jovens e a função exige conhecimentos em diversas áreas da gestão organizacional.

O terceiro segmento pesquisado está relacionado às competências dos controllers, buscando conhecer quais são mais utilizadas por eles, seguindo a classificação de Fleury e Fleury (2011) e Fleury (2009). Foram listadas 59 competências subdivididas em 20 competências Técnicas, 21 Sociais e 18 de Negócio, baseadas no levantamento bibliográfico.

As Competências Sociais que os controllers têm e Usam Muito, foram as listadas como de maior intensidade de uso, dentre todas as competências estudadas, com praticamente nenhuma identificada como não sendo usada. Um percentual de $10 \%$ da amostra registrou que pouco utiliza apenas quatro dentre as 21 competências listadas, o que não é significativo. Outro aspecto interessante são as seis que obtiveram 100\% de uso. Ou seja, a grande maioria das Competências Sociais foram listadas como de muito uso ou geralmente usam.

A análise das Competências Sociais que os controllers têm e Usam Muito:

- $100 \%$ de muito uso: interage bem com as pessoas; tem integridade e confiança; sabe trabalhar em equipe; comunica-se oralmente com clareza; escreve com clareza e objetividade; tem postura proativa e realizadora.

- Entre 60\% e 90\% dos respondentes afirmaram usar muito: possui liderança e sabe gerir pessoas; tem flexibilidade nas relações interpessoais; sabe formar equipes cooperativas e comprometidas, capacidade de autocrítica; controle emocional; estimula o desenvolvimento da equipe; adapta-se bem às mudanças; estimula o aprendizado da equipe; sabe ouvir os outros; é persistente e não desiste frente aos obstáculos; tem capacidade de prever problemas interpessoais; tem flexibilidade nas relações interpessoais; gerencia conflitos no ambiente de trabalho e interage bem com as pessoas.

Nascimento e Reginato (2010) destacam atributos que estão em consonância com essas constatações como liderança, ética, capacidade de comunicação, capacidade de cooperação, persuasão, ponderação e trabalho em equipe. Brewer (2008) também defende que a controladoria deve trabalhar com: liderança, gestão estratégica, alinhamento operacional, melhoria e aprendizado contínuos; e gerar valor para os acionistas.

As competências sociais que são apontadas como Pouco Usadas foram apenas quatro, por 10\% dos participantes: gerenciamento de conflitos no ambiente de trabalho, tem controle emocional, sabe formar equipes comprometidas e cooperativas, e tem flexibilidade nas relações interpessoais, mas novamente não significativas em termos do contexto relativo aos demais pesquisados.

Esses dados relativos às Competências Sociais são muito interessantes, pois levantam a questão da preocupação com o ambiente de trabalho e com a gestão de pessoas, que são importantes para obter resultados positivos, a partir das relações pessoais, visando os melhores resultados para a empresa e para as pessoas. Podem ser vistos como reflexo da atuação gerencial dos controllers pesquisados, que vem crescendo com o passar do tempo, deixando de atuar meramente no nível operacional, para galgar postos gerenciais e estratégicos, em muitas organizações, seguindo estudos como os de Lunkes, Schnorrenberger e Rosa (2013), dentre outros.

As Competências de Negócio são as que estão relacionadas à interação da empresa com o ambiente, pontos fortes e fracos do negócio e que são orientadas para as exigências do mercado. Foram listadas 18 competências para que os pesquisados marcassem seu uso. Interessante salientar que nas empresas prestadoras de serviços jurídicos foram iden- 
tificados os maiores índices de não ou pouco uso destas competências. Apenas em uma das competências listadas (Faz análise do risco organizacional) não foi identificada a maioria em geralmente usa ou usa muito, como em todas as demais. Competências de Negócio que os controllers têm e Usam Muito:

- Entre $60 \%$ e $90 \%$ dos respondentes usam muito: tem capacidade de tomar decisão com imparcialidade; pensa e age estrategicamente.

- Em 50\% que usam muito: sabe organizar o tempo para realizar diversas atividades; tem foco na qualidade em todas as decisões que toma; busca melhoria contínua nos processos que participa; tem orientação para cliente/fornecedor.

Essas competências de Negócio estão relacionadas ao apoio gerencial e estratégico dos controllers à organização e autores como Lunkes, Schnorrenberger e Rosa (2013), dentre outros, destacam a importância dessas competências na atuação profissional dos controllers em seus estudos. Padoveze e Benedicto (2005) também destacam o exercício da função gerencial, apoio estratégico e o controle de informações.

Quando analisadas as opções Geralmente Usa em conjunto com Usa Muito, dentre as Competências de Negócio, a maciça maioria está listada desta forma, à exceção apenas da competência Faz análise de Risco Organizacional. Isto de certo modo surpreendeu, pois diversos autores defendem que os controllers atuam na gestão de risco, como Borinelli (2006) e Padoveze e Benedicto (2005).

A análise dos resultados quanto às Competências Técnicas dos controllers investigados mostrou novamente que dentre as empresas pesquisadas, as prestadoras de serviços jurídicos foram as que registraram maiores índices de Não ou Pouco Uso do maior número de competências da amostra trabalhada. Foram listadas nestas categorias as competências técnicas de: fornece dados contábeis oportunos e precisos; supervisiona o funcionamento de toda a empresa; supervisiona a contabilidade.

Em relação às competências Técnicas que os controllers têm e Usam Muito:

- Entre 50\% e 80\% dos respondentes usam muito: gerencia indicadores de desempenho; assessora a cúpula administrativa; fornece suporte informacional à gestão organizacional.

Quando analisadas as demais Competências Técnicas nas opções Geralmente Usa e Muito Usa, dez delas foram identificadas pela maioria, que são: conhecimentos da área financeira; conhecimentos na área de TI - Tecnologia da Informação; conhecimentos na área de Recursos Humanos; conhecimentos na área comercial/produção; elabora diretrizes de controles internos; elabora o orçamento anual; gerencia indicadores de desempenho; supervisiona o funcionamento de todos os setores da empresa; elabora relatórios gerenciais; elabora o planejamento financeiro organizacional.

Esses dados mostram que os controllers que participaram desta pesquisa estão mais ligados à gestão organizacional, tendo deixado de ser apenas trabalhadores operacionais para serem gerenciais e de apoio estratégico às organizações, o que segue a tendência da área de controladoria de ser mais efetiva no assessoramento à gestão organizacional, confirmando estudos como os de Koliver (2005), Zoni \& Kenneth (2007), Lunkes, Schnorrenberger e Rosa (2013) e Vargas e Beuren (2012).

\section{CONSIDERAÇÕES FINAIS}

A pesquisa que subsidiou este artigo buscou responder à seguinte questão: qual é o perfil e quais as competências que o controller deve possuir? O objetivo geral da pesquisa foi, então, levantar as competências mais utilizadas pelos Controllers no exercício de suas atividades em empresas de Recife, em Pernambuco.

Como a Controladoria é uma área do conhecimento relativamente nova e que abrange além dos preceitos básicos da contabilidade, preceitos administrativos, gerenciais e informacionais, ainda há bastante espaço para estudar a sua práxis em organizações e realidades diversas, uma vez que grande parte do que se desenvolve na controladoria depende do contexto em que ela está inserida, incluindo os recursos disponíveis que vão desde os recursos materiais e tecnológicos aos recursos humanos, com suas formações, experiências e nível de envolvimento.

Associada a essa realidade está a atuação do profissional que atua na Controladoria e que nem mesmo uma nomenclatura uniforme foi ainda estabelecida. Neste trabalho, optou-se por utilizar o termo controller, para o profissional que atua na controladoria ou desenvolve suas atividades e funções.

Este artigo é parte de um estudo mais amplo que vem buscando conhecer as peculiaridades das competências desse profissional, em empresas de porte e segmentos diversos, com objetivo de auxiliar na construção do seu perfil profissional e exigências das empresas em termos de competências, para o bom desempenho da função.

Foi identificado o perfil das empresas pesquisadas, como maioria de grande e médio porte, com metade da amostra formada por empresas prestadoras de serviços. Interessante salientar que mesmo dentre as empresas de pequeno porte e muitas médias também, em que não há um setor de controladoria estabelecido, foi claramente identificado que as atividades de controladoria são realizadas.

Em termos do perfil dos controllers ou profissionais que desempenham as atividades de controladoria nas empresas participantes, são profissionais em maioria mulheres, jovens, graduadas em Administração, Ciências Contábeis e Direito, com experiência na área entre 10 e 20 anos.

Quanto às competências analisadas segundo a classificação de Fleury e Fleury (2011), inicialmente foram analisadas as Competências Sociais que os controllers têm e Usam Muito, salientando que foram as listadas como de maior 
intensidade de uso dentre todas as competências estudadas, com praticamente nenhuma delas identificada como não sendo usada. Foram as competências em que se identificou $100 \%$ de muito uso: interage bem com as pessoas; tem integridade e confiança; sabe trabalhar em equipe; comunica-se oralmente com clareza; escreve com clareza e objetividade; tem postura proativa e realizadora.

$\mathrm{Na}$ análise das Competências de Negócio as que estão relacionadas à interação da empresa com o ambiente e orientadas para as exigências do mercado, foram listadas 18 competências baseadas no levantamento bibliográfico realizado e é interessante salientar que nas empresas prestadoras de serviços jurídicos foram identificados os maiores índices de não ou pouco uso destas competências. A maioria dos participantes afirmou que usa muito as competências: tem capacidade de tomar decisão com imparcialidade e pensa e age estrategicamente. Isto vem confirmar a ampliação da atuação do profissional da controladoria para o nível gerencial e/ou estratégico, conforme levantamento bibliográfico realizado.

Quanto à análise das Competências Técnicas dos controllers pesquisados, a maioria usa muito as competências: gerencia indicadores de desempenho; assessora a cúpula administrativa e fornece suporte informacional à gestão organizacional. Mais uma vez foi demonstrado que estes profissionais estão desenvolvendo atividades gerenciais e de apoio à alta administração, deixando de serem meros trabalhadores operacionais, confirmando, mais uma vez, a tendência de ampliação das atividades desenvolvidas pelos controllers.

Apesar das limitações do estudo, interessantes constatações foram identificadas que podem ser subsídios para novos estudos em outras realidades e organizações para ampliar o entendimento das funções e competências dos controllers no Brasil.

\section{REFERENCIAL BIBLIOGRÁFICO}

AMORIM, T. N. G. F; SILVA, L. B. Gestão por competências: nuances e peculiaridades. Reuna, Belo Horizonte, v. 16, n. 1, p. 103-119, jan./abr. 2011.

AMORIM, T. N. G. F. Gestão de pessoas no agronegócio. In: Callado, Antônio André Cunha (Org.). Agronegócio. 4. ed. São Paulo: Atlas, 2014 .

ANTHONY. R. N.; GOVINDARAJAN, V. Sistemas de controle gerencial. São Paulo: Atlas, 2002.

BATISTA, K.; CANÇADO V.L. Competências requeridas para a atuação em coaching: a percepção de profissionais coaches no Brasil. Revista de Gestão, v. 24, p. 24-34, 2017.

BEUREN, I. M. O papel da controladoria no processo de gestão. In: SCHMIDT, P. (Org.). Controladoria agregando valor para a empresa. Porto Alegre: Bookmann, 2002.

BEUREN, I. M; MIILER, E. T. C. Evidências de institucionalização da controladoria em empresas familiares. Revista de Administração FACES Journal, v. 9, n. 2, p. 43-63, 2010

BEUREN, I. M; BOGONI, N. M.; FERNANDES, L. Análise da abordagem da controladoria em dissertações dos programas de pós-graduação em Ciências Contábeis. Revista Brasileira de Gestão de Negócios, São Paulo, v. 10, n. 28, p. 249-263, 2008.

BORINELLI, M. L. Estrutura básica conceitual de controladoria: sistematização à luz da teoria e da prática. $2006.341 \mathrm{f}$. Tese (Doutorado em Ciências Contábeis) - Faculdade de Economia, Administração e Contabilidade, Universidade de São Paulo, São Paulo, 2006

BRAGG, S. M. Controllership: the work of the managerial accountant. 8 ed. New Jersey: John Wiley \& Sons, 2009.

BREWER, Peter C. Redefining management accounting. Strategic Finance, Montvale, v. 89, n. 9, p. 35-43, 2008.

BROADBENT, J.; LAUGHLIN, R. Organizational and accounting change: Theoretical and empirical reflections and thoughts on a future research agenda. Journal of Accounting \& Organizational Change, v. 1, n.1, p. 7-25, 2005.

CALlado, A. A. C.; AMORIM, T. N. G. F. Competências da Função de Controller em Hotéis de Grande Porte da Região Metropolitana do Recife. Revista Evidenciação Contábil \& Finanças, v. 5, n. 2, p. 57-73, 2017.

CARDOSO, R. L. Competências do Contador: Um estudo empírico. 2006. 169 f. Tese de Doutorado em Ciências Contábeis - Departamento de Contabilidade e Atuária, Universidade de São Paulo, São Paulo, 2006.

CAVALCANTE, D. S.; LUCA, M. M. M. de; PONTE, V. M. R.; GALLON, A. V. Características da controladoria nas maiores companhias listadas na BM \& F Bovespa. Revista Universo Contábil, v. 3, n. 8, p. 113-134, 2012.

CRISPIM, G.; CABRAL, L. M. M. do A. C.; LIBONATI, J. J. Aspectos comportamentais: A controladoria como fator de influência no comportamento humano. Advances in Scientific and Applied Accounting, v. 4, n.3, p. 379-405, 2011.

DALMACIO, F. Aderência entre o conceito e a prática das funções atribuídas ao controller: um estudo no contexto brasileiro. In: Anais do Congresso Internacional de Custos. 2007. 
DUQUE, C. F. O perfil profissional do Controller e as funções de Controladoria: um estudo da atual necessidade do mercado de trabalho. Dissertação, Mestrado em Ciências Contábeis, UFPE, 2011.

DUTRA, J. S. Gestão por competências: um modelo avançado para o gerenciamento de pessoas. São Paulo: Gente, 2004.

DUTRA, J. S.; FISCHER, A. L.; RUA, R. DE L.; NAKATA, L. E. Absorção do Conceito de Competência em Gestão de Pessoas... In: DUTRA, J. S.; FLEURY, M. T. L.; RUAS, R. (Orgs.). Competências: conceitos, métodos e experiências. São Paulo: Atlas, 2008.

EMSLEY, D. Restructuring the management accounting function: a note on the effect of role involvement on innovativeness. $M a-$ nagement Accounting Research, v. 16, n. 2, p. 157-177, 2005.

FERNANDES, A. A; GALVÃO, P. R. A Controladoria como ferramenta de gestão nas micro e pequenas empresas. Revista de tecnologia aplicada, v.5, n.1, jan./abr., p. 3-16, 2016.

FERNANDES, B.; COMINI, G. Limitações na estruturação de modelos de gestão por competências: uma análise de organizações líderes em diversos setores. In: XXXII Encontro Anual da ANPAD. Anais ... Rio de Janeiro: ANPAD, 2008.

FIGUEIREDO, S.; CAGGIANO, P. C. Controladoria: teoria e prática. 3 ed., São Paulo: Atlas, 2008.

FLESCH, V. Controladoria como suporte de gestão das indústrias moveleiras na Região Oeste de Santa Catarina. Revista Catarinense da Ciência Contábil, v. 9, n. 27, p. 79-92, 2010

FLEURY, A.; FLEURY, M. T. L. Estratégias empresariais e formação de competências: um quebra-cabeça caleidoscópico da indústria

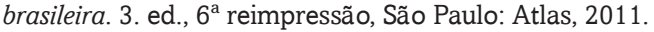

FLEURY, M. T. L.; FLEURY, A. C. C. Construindo o conceito de competência. Revista de Administração Contemporânea, Curitiba, v. 5, n. especial, 2001. Disponivel em: <http://www.scielo.br/scielo.php?script=sci_arttext\&pid=S1415-65552001000500010>. Acesso em: 05 jul. 2016

FLEURY, M. T. L.; FLEURY, A. C. C. Organizational culture and the renewal of competences. BAR. Brazilian Administration Review, v. 6, n. 1, p. 1-14, 2009

FLEURY, M. T. L.; FLEURY, A. C. C. Construindo o conceito de competência. Revista de administração contemporânea, v. 5, n. ESPE, p. 183-196, 2001

FIGUEIREDO, S.; CAGGIANO, P. C. Controladoria: teoria e Prática. 5. ed. São Paulo: Atlas, 2008.

GARAVAN, T.; MCGUIRE, D. Competencies \& Workplace Learning: Some Reflections on the Rhetoric \& the Reality, Journal of Workplace Learning, v. 13, n. 4, p. 144-164, 2001.

GIL, A. C. Como elaborar projetos de pesquisa. 5. ed. São Paulo: Atlas, 2010.

GUIMARÃES, I. C.; PARISI, C.; PEREIRA, A.C.; WEFFORT, E.F.J. A importância da Controladoria na gestão de risco de empresas não-financeiras: um estudo na percepção de gestores de risco e controllers. Revista Brasileira de Gestão de Negócios, São Paulo, v. 11, n. 32, p. 260-275, 2009.

HAMDAN, A. M. M. The impact of company size, debt contracts, and type of sector on the level of accounting conservatism: an empirical study from Bahrain. International Journal of Business and Management, v. 6, n. 7, p. 134-146, 2011.

HORNGREN, C. T.; SUNDEM, G.L.; STRATTON, W.O. Contabilidade gerencial. 12. ed. São Paulo: Pearson, 2004.

KOLIVER, O. A Contabilidade e a Controladoria, tema atual e de alta relevância para a profissão contábil. Porto Alegre: CRC/RS, 2005

KÜPPER, P. Controlling: Konzeption, Aufgaben und Instrumente, 4. Auflage. Berlin: MSG, 2005.

LE BOTERF, G. Desenvolvendo a competência dos profissionais, 3. ed. São Paulo: Artmed, 2007.

LAMBERT, C.; SPONEM, S. Roles, authority and involvement of the management accounting function: a multiple case-study perspective. European Accounting Review, v. 21, n. 3, p. 565-589, 2012.

LOURENSI, A.; BEUREN, I. Inserção da Controladoria em teses da FEA/USP: uma análise nas perspectivas dos aspectos conceitual, procedimental e organizacional. Contabilidade Vista \& Revista, v. 22, n. 1, p. 15-42, 2011.

LUNKES, R. J; SCHNORRENBERGER. D. Controladoria: na coordenação dos sistemas de gestão, São Paulo: Atlas, 2009.

LUNKES, R. J; SCHNORRENBERGER. D.; GASPARETTO, V. Um estudo sobre as funções da controladoria. Revista de Contabilidade e Organizações, v. 4, n. 10, art. 6, p. 106-126, 2010.

LUNKES, R. J; SCHNORRENBERGER. D.; ROSA, F.S. da. Funções da Controladoria: uma análise no cenário Brasileiro. Revista Brasileira de Gestão de Negócios, v. 15, n. 47, p. 283-289, 2013.

MACHADO, A. O., LUNKES, R. J., PETRI, S. M.; ROSA, F. S. Competências do Controller: um estudo nas 100 maiores empresas de Santa Catarina. Revista Pensar Contábil, v.12, n.47, p. 26-34, 2013. 
MARTINS, P.L.; BARBOSA, F.F.; MESQUITA, F.F.de; SILVA, P.D.; LUCINDO, Y. S. os A Importância da Controladoria na Avaliação de Desempenho, Anais..., X SEGeT, 2012.

MEDEIROS, I. B.de O. Gestão por competências: uma abordagem estratégica adaptada à pequena empresa, Revista de Administração e Inovação, São Paulo, v. 4, n. 2, p. 49-66, 2007.

NASCIMENTO, A. M.; REGINATO, L. Controladoria: Instrumento de apoio ao processo decisório, São Paulo: Atlas, 2010.

NASCIMENTO, F. R.V.; ROSA, A. L. T.; SANTOS, S. M.; TENÓRIO, J. N. B. A Controladoria como Suporte ao Processo de Gestão numa Empresa do Comércio Varejista. Revista de Contabilidade do Mestrado em Ciências Contábeis da UERJ, Rio de Janeiro, v. 10, n. 2, p.1-16, 2005. Atlas, 2011.

OLIVEIRA, L.M.; PEREZ JR., J.H.; e SILVA, C.A.S. Controladoria Estratégica: textos e casos práticos com solução. 8ª . Ed. São Paulo:

PADOVEZE, C. L.; BENEDICTO, G. C. Cultura organizacional: análise e impactos dos instrumentos no processo de gestão. Revista de Administração, v. 11, n. 2, mar./abr., 2005.

RAHMAN, S.; AHMED, J. U. An evaluation of the changing role of management accountants in recent years. Indus Journal of Management \& Social Science, v. 6, n. 1, p. 18-30, 2012.

REIS, A. de O.; SEDIYAMA, G. A. S.; MOREIRA, V. de S.; MOREIRA, C. C. Perfil do Profissional Contábil: Habilidades, Competências e Imagem Simbólica. Revista Contemporânea de Contabilidade, v. 12, n. 25, p. 95-116, 2015.

RODRIGUES, H. G.; BRUSTEIN, J. A Relação entre Desaprendizagem e o Desenvolvimento de Competências Individuais na Implantação de um Sistema de Gestão da Qualidade. Revista Economia \& Gestão, v. 16, n. 44, p. 51-80, 2016.

RUAS, R.; GHEDINE, T.; DUTRA, J.; BECKER, G.; DIAS, G. O Conceito de Competência de A à Z - análise e revisão nas principais publicações nacionais entre 2000 e 2004. In: Anais do XXIX Encontro Anual da Associação Nacional dos Programas de Pós-Graduação em Administração. Brasília: ANPAD, 2005.

SCHMIDT, P.; SANTOS, J. L. dos. A Controladoria e a análise discriminante do consumidor do e-commerce. Revista Internacional de Economia y Gestion de las Organizaciones, v. 3, p. 1-15, 2014.

SOUSA, K. A.; BASSOLLI, R. Contabilidade gerencial um instrumento de apoio a gestão para a tomada de decisão, 2013. Disponível em: <http://www.ice.edu.br/TNX/storage/webdisco/2013/12/13/outros/555a4ca9721653f157cd87c71daed621.pdf>. Acesso em: 20 jun. 2016.

TAKATORI, R. S. Gestão estratégica: a necessidade de rever o modelo de controladoria para atender as novas necessidades dos agentes de mercados stakeholders. Anais..., do Congresso Brasileiro de Custos-ABC, 2004

VARGAS, J. A.; BEUREN, I. M. O envolvimento do controller no processo de gestão: um estudo em empresas brasileiras. Advances in Scientific and Applied Accounting, v. 5, n.3, p. 405-426, 2012.

ZONI, L.; KENNETH, M. Controller involvement in management: an empirical study in large Italian corporations. Journal of Accounting \& Organizational Change, v. 3, n.1, p. 29-43, 2007. 